\title{
Colangiocarcinoma Associado a Retocolite Ulcerativa: Relato de Caso e Revisão de Literatura
}

\author{
Cholangiocarcinoma and Ulcerative Colitis: \\ Case Report and Literature Review
}

\author{
JUVENALDA ROCHATORRES NETO ${ }^{1}$, RODRIGOR. SANTIAGO ${ }^{2}$, ANACAROLINALISBOAPRUDENTE $^{3}$, DAN \\ RODRIGUES MARIANO ${ }^{4}$, FERNANDAMENDONÇARAMOS ${ }^{5}$, FELIPEAUGUSTO DO PRADOTORRES ${ }^{6}$, JÚLIO \\ AUGUSTO DO PRADO TORRES ${ }^{7}$, RAQUEL MATOS DE SANTANA $^{8}$
}

${ }^{1}$ Professor, doutor e chefe do Serviço de Coloproctologia da UFS, ${ }^{2}$ Residente de Coloproctologia da UFS, ${ }^{3}$ Residente
de Coloproctologia da UFS, ${ }^{4}$ Residente de Coloproctologia da UFS,,${ }^{5,6,7,8}$ Acadêmicos de Medicina da UFS. TORRES NETO JR; SANTIAGO RR; PRUDENTE ACL; MARIANO DR; RAMOS FM; TORRES FAP TORRES JAP; SANTANA RM. Colangiocarcinoma Associado a Retocolite Ulcerativa: Relato de Caso e Revisão de Literatura. Rev bras Coloproct, 2010;30(1): 087-091.

RESUMO: A Retocolite Ulcerativa (RCU) é uma doença inflamatória intestinal crônica, que acomete a camada mucosa do intestino grosso, e que pode estar associada a manifestações extra-intestinais, como a colangite esclerosante que pode malignizar para colangiocarcinoma. Relatamos um caso de paciente do gênero masculino, 21 anos, procedente de Poço Redondo-SE, natural de Cubatão-SP, admitido no Hospital Universitário da Universidade Federal de Sergipe em 23 de maio de 2008 , com RCU associada à colangite esclerosante e colangiocarcinoma.

Descritores: Retocolite Ulcerativa, colangite esclerosante, colangiocarcinoma.

\section{INTRODUÇÃO}

A RCU caracteriza-se por uma inflamação superficial da mucosa intestinal, acometendo principalmente suas partes distais (especificamente o reto), podendo, contudo, ascender às suas partes proximais, sempre em continuidade, caracterizando a pancolite. Os sintomas mais freqüentes são diarréia crônica mucopiossanguinolenta, acompanhada de dor e distensão abdominal, perda de peso, inapetência, tenesmo, além de alguns casos cursarem com febre, taquicardia, desaparecimento de ruídos hidroaéreos e desequilíbrio hidroeletrolítico. ${ }^{1,2}$

Esta entidade comumente encontra-se acompanhada de manifestações extra-intestinais, tais como eritema nodoso, pioderma gangrenoso, artrite, uveíte, colangite esclerosante e câncer colorretal. Dentre essas, destacamos a colangite esclerosante que, pelo risco de malignizar para colangiocarcinoma, apresenta altos índices de morbimortalidade em curto período de tempo e, apesar de raro na população em geral, é relativamente comum em pacientes com RCU. Trabalhos recentes mostram que cerca de $5 \%$ dos pacientes com RCU são acometidos pela colangite esclerosante e desses, 10 a $15 \%$ desenvolvem o colangiocarcinoma. ${ }^{3,4}$

Pacientes com RCU e colangiocarcinoma apresentam um quadro clínico caracterizado pela presença de massa hepática expansiva, podendo haver sintomas obstrutivos, febre, suor noturno, perda de peso e dor em quadrante superior direito do abdômen. O tratamento indicado varia de acordo com o grau da malignização, podendo-se realizar a ressecção do tumor, quimioterapia adjuvante, além do tratamento sintomático. Até o momento o tratamento cirúrgico é o que oferece melhores chances de cura. ${ }^{5}$

Trabalho realizado no Serviço de Coloproctologia do Hospital Universitário de Sergipe (HU-SE) - SE - Brasil.

Recebido em 19/06/2009

Aceito para publicação em 15/07/2009 
Rev bras Coloproct

Janeiro/Março, 2010
Colangiocarcinoma Associado a Retocolite Ulcerativa:

Relato de Caso e Revisão de Literatura

Juvenal da Rocha Torres Neto e Cols.
Vol. 30

$\mathbf{N}^{\mathbf{0}} 1$

\section{RELATO DE CASO}

F.G., gênero masculino, 21 anos, foi admitido no Hospital Universitário da Universidade Federal de Sergipe apresentando queixa de diarréia crônica há aproximadamente seis anos. Durante esses anos procurou atendimento médico e foram prescritos vermífugos e outros paliativos para tratamento sintomático, sem a elucidação diagnóstica. Durante a consulta relatou que há dois meses houve intensificação dos sintomas, com diarréia sanguinolenta (pastosas/líquidas, $8 \mathrm{x} / \mathrm{dia}$ ), dor abdominal em epigástrio e flanco esquerdo, perda ponderal (10kg/2meses), febre, icterícia e colúria. Foi realizada colonoscopia, confirmando o diagnóstico de RCU grave (Figura 1). Durante os dez dias seguintes, houve manutenção do quadro, com edema em membros inferiores e ascite. Ao exame físico apresentou-se em estado geral regular, acianótico, ictérico $(2+/ 4+)$, desidratado $(2+/ 4+)$, hipocorado $(3+/$ $4+)$ e taquicárdico (FC:116 bpm), com creptos em bases pulmonares, abdômen distendido, tenso e doloroso à palpação difusamente. Dos exames solicitados, o sumário de urina mostrou presença de bilirrubina, sangue e Hb (3+), e piócitos (10 por campo); raio-x de abdômen com distensão e edema de alças intestinais, principalmente do cólon transverso, fazendo pensar na possibilidade de RCU fulminante ou megacólon tóxico; US abdominal total demonstrou lesão expansiva heterogênea em lobo hepático esquerdo (segmentos I, II, III), ascite volumosa e espessamento da parede da vesícula biliar; TC de abdômen também demonstrou massa expansiva hepática e cólon bastante distendido (Figura 2). O paciente apresentou um quadro de abdômen agudo, sendo realizada laparotomia exploradora de urgência (Figura 3), que evidenciou volumosa tumoração hepática, a qual foi biopsiada e enviada ao exame anatomopatológico, com confirmação de neoplasia maligna pouco diferenciada em fígado (Figura 4). Foi solicitado, ainda, estudo iminohistoquímico-imunocitoquímico com conclusão de colangiocarcinoma. Em função da gravidade o paciente foi a óbito no $17^{0} \mathrm{DPO}$.

\section{DISCUSSÃO}

A RCU é uma doença inflamatória intestinal de causa é desconhecida, mas acredita-se que fatores genéticos, auto-imunes e ambientais sejam determinantes para seu aparecimento. Essa entidade clínica apresenta distribuição variável no mundo, po-

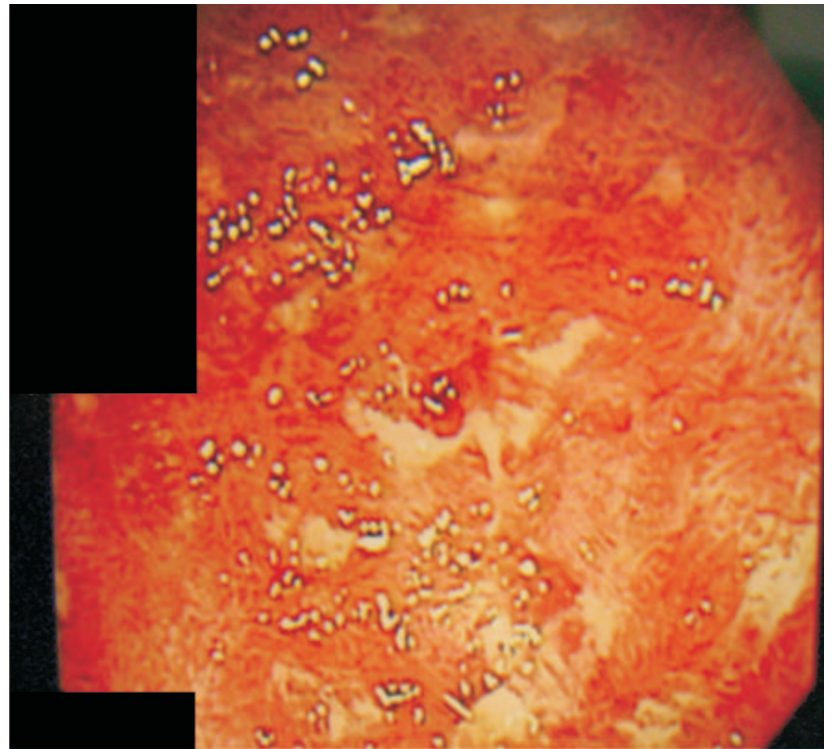

Figura 1 - Colonoscopia evidenciado processo inflamatório grave com úlceras superficiais, áreas recobertas por muco e pus, presença de edema, friabilidade e sangramento.

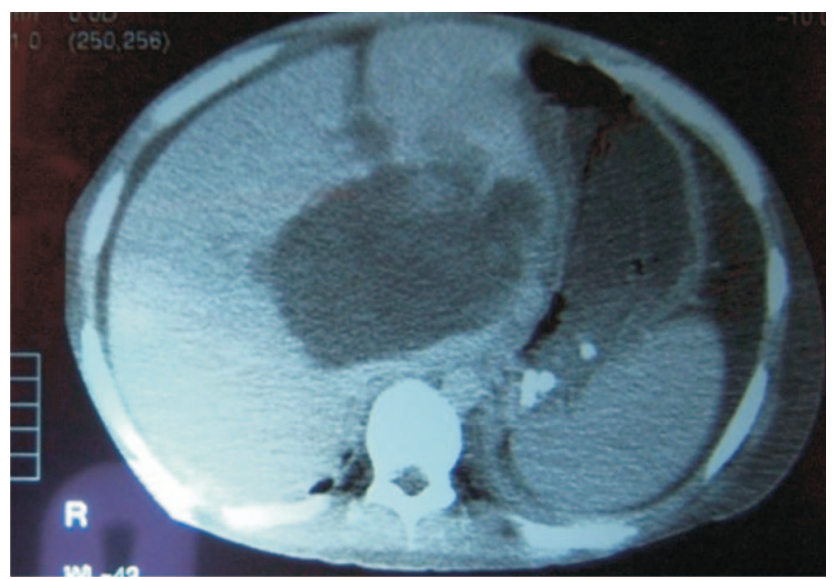

Figura 2 - Tomografia de abdômen com presença de cólon distendido e massa expansiva hepática, heterogênea, de contornos irregulares e multilobular; vesícula biliar bastante distendida, com paredes espessadas, e com cálculos em seu interior.

rém tem-se notado um aumento crescente de sua incidência nos países em desenvolvimento. SEPULVEDA et al demonstraram que, de um total de 258 pacientes atendidos no serviço de Coloproctologia do Hospital Clínico da Universidade do Chile, 59\% foram diagnosticados com RCU. Outros trabalhos, como o de LOFTUS, mostram uma alta incidência de RCU nos EUA e na Europa (1,4 milhão e 2,2 milhões, respectivamente). No Brasil, estudos epidemiológicos recentes sugerem que sua incidência está aumentando, apesar de desconhecermos sua taxa real. SOUZA et al, 


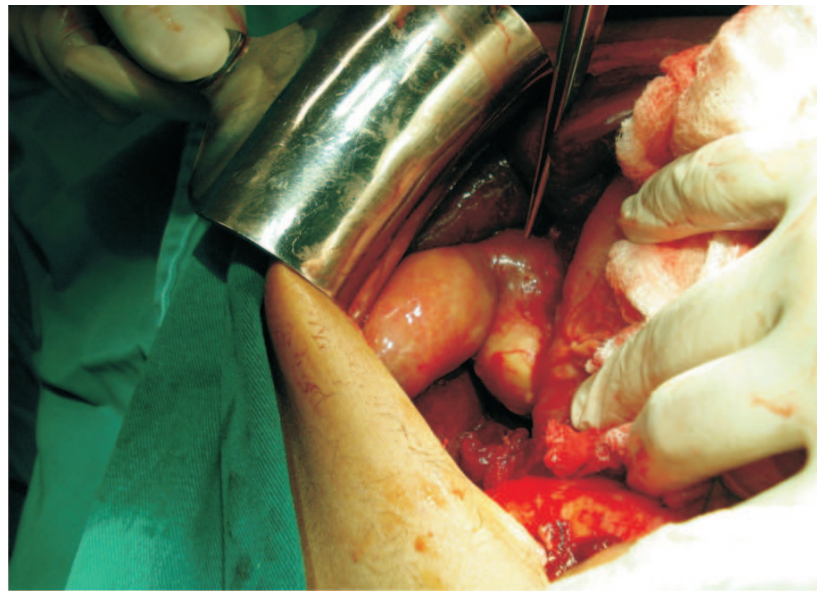

Figura 3-Laparotomia: vesícula de parede espessada e distendida; e dilatação do hepato-coledoco.

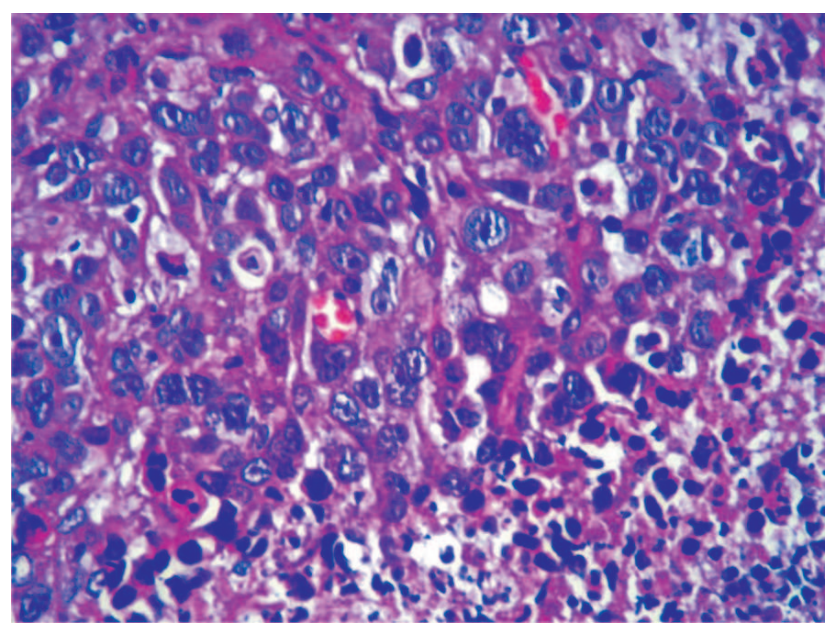

Figura 4 - Anátomo-patológico: presença de células pouco diferenciadas, de origem epitelióide, com conteúdo citoplasmático volumoso e núcleos grandes, indicando a presença de neoplasia maligna pouco diferenciada de células epitelióides e padrão sólido.

em 2008 avaliaram o perfil epidemiológico dos pacientes com doença inflamatória intestinal que residiam no estado de Mato Grosso, encontrando 220 pacientes com doença inflamatória intestinal, e desses, 117 (53\%) eram portadores de RCU. . $7,8^{-1}$

Mais da metade dos pacientes acometidos pela RCU apresentam alguma manifestação extra-intestinal, que pode muitas vezes evoluir de forma mais grave que a própria RCU e levar o paciente a óbito. Estudos mostram que dessas manifestações, as mais freqüentes são as articulares, as dermatológicas, as hepato-biliares e as do trato urinário. Dentre essas, destacamos as alterações hepáticas por levarem, não raramente, a complicações mais graves. A incidência de doença hepática significativa, identificada pela presença de anormalidades bioquímicas de função hepática, chega a $8,2 \%$. São comumente observadas: colelitíase, esteatose, pericolangite, colangite esclerosante, fígado reacional, cirrose, abscessos hepáticos e câncer da árvore biliar., ${ }^{9,10}$

A colangite esclerosante (CE) é uma doença colestática crônica e progressiva do fígado, caracterizada por inflamação, obliteração e fibrose da árvore biliar intra e extra hepática. É rara na população em geral, mas é muito comumente associada à RCU, acometendo mais de $5 \%$ desses pacientes, de modo que a grande maioria dos pacientes com colangite esclerosante (mais de 90\%), também apresenta doença inflamatória intestinal. Normalmente a doença inflamatória intestinal precede a CE, embora possa ocorrer o inverso, ou mesmo durar longo período de tempo entre o aparecimento de uma e outra. A CE é mais comum entre a quinta e sétima década de vida e predomina no gênero masculino; o risco aumenta em pacientes com história familiar positiva para $\mathrm{CE}$, sugerindo predisposição genética. Embora sua etiologia precisa continue desconhecida, acredita-se que seja uma doença imuno-mediada. Os sinais e sintomas mais freqüentes são febre, icterícia e leucocitose, e resulta, após cinco ou dez anos, em cirrose biliar secundária, e morte por insuficiência hepática. O tratamento é feito com altas doses de ácido ursodesoxicólico, que oferece alguma proteção com relação ao curso da doença: lentifica o processo de fibrose hepática e no aspecto colangiográfico, reduz a sintomatologia, e a incidência de displasia e câncer colorretal associados. A terapia endoscópica (usualmente a dilatação com balão) é efetiva para estenoses benignas que podem causar icterícia. O transplante hepático é o único tratamento nos estágios finais da doença, embora a chance de recidiva ocorra em cerca de $1 / 3$ dos pacientes, e a incidência de câncer colorretal após transplante seja de 5 a $10 \%$. É indispensável que seja realizada colonoscopia anual nesses pacientes a fim de acompanhar o curso da doença. ${ }^{11,12}$

O colangiocarcinoma é também uma grave complicação da CE, com um risco de 10 a $15 \%$ para esses pacientes. Sua instalação inviabiliza o transplante hepático e piora bastante o prognóstico dos pacientes. A incidência de colangiocarcinoma na CE é muito alta, variando de 14-28\% nas séries mais recentes. O diagnóstico é muito difícil, e não é feito em um grande número de casos. Níveis séricos de CA 19-9 e CEA 
poderiam identificar os pacientes com CE que desenvolveriam colangiocarcinoma. Sua utilidade precisa, porém, ser confirmada em estudos prospectivos. Aparentemente, níveis elevados de CEA na bile estariam diretamente correlacionados com o desenvolvimento de colangiocarcinoma. A expressão da forma mutante da proteína tumoral p53 foi detectada em biópsias hepáticas de pacientes com CE e colangiocarcinoma, inclusive em epitélio biliar em áreas não afetadas pelo tumor. Talvez num futuro recente a coloração imunohistoquímica para $\mathrm{p} 53$ venha a ser rotineiramente utilizada nos pacientes com CE, e sua detecção em epitélio biliar contra-indicaria o transplante hepático. $\mathrm{O}$ ideal seria identificar os pacientes de risco para o desenvolvimento de colangiocarcinoma, e nestes indicar precocemente o transplante. ${ }^{13,14}$

O diagnóstico do colangiocarcinoma foi realizado inicialmente através da tomografia, quando se evidenciou massa hepática expansiva, em seguida a laparotomia exploradora de urgência evidenciou tumoração hepática volumosa (que se estendia até o hilo hepático, duodeno e pâncreas), vesícula distendida e com paredes espessadas, e dilatação do hépatocolédoco. Foi realizada a biópsia hepática e da massa tumoral próxima ao duodeno e, em seguida, a colecistostomia. A imuno-histoquímica confirmou o diagnóstico de colangiocarcinoma.

O tratamento varia de acordo com o grau da malignização, podendo-se realizar a ressecção do tumor, quimioterapia adjuvante, além do tratamento sintomático.

No presente caso, em função da gravidade do caso realizou-se apenas a biópsia da lesão hepática e colecistostomia com a intenção de reduzir o nível de icterícia, embora soubéssemos ser um opção cirúrgica ruim.

Relatamos um caso de colangite esclerosante com colangiocarcinoma associado a RCU, patologia ainda não tão freqüente no nosso meio e portanto, menos ainda essa manifestação extra-intestinal.

\footnotetext{
ABSTRACT: The Ulcerative Colitis (UC) is a cronic inflamatory bowel disease, that affects the mucosa of the large bowel and which can be associated with extra-intestinal manifestations, such as slcerosing cholangitis, an illness that could become a cholangicarcinoma. We reported a case of a male patient, 21-year-aged, from Poço Redondo-SE, who was born in Cubatão-SP and admitted in the Hospital Universitário of the Universidade Federal de Sergipe, on may 23 at the year 2008 with UC associated with sclerosing cholangitis and cholangiocarcinoma.
}

Key words: Ulcerative colitis, sclerosing cholangitis, cholangiocarcinoma.

\section{REFERÊNCIAS}

1. Ioshii S O et al - Megacólon tóxico fatal por cytomegalovirus em paciente com retocolite ulcerativa idiopática: relato de caso e revisão de literatura. Arq Gastroenterol, São Paulo, vol. 39, n. 2, abr.-jun. 2002.

2. Souza M H L P et al - Evolução da ocorrência (1980-1999) da doença de Crohn e da retocolite ulcerativa idiopática e análise das suas características clínicas em um hospital universitário do sudeste do Brasil. Arq Gastroenterol 2002; 39(2).

3. Pohl $\mathrm{C}$ et al - Chronic inflammatory bowel disease and cancer. Hepatogastroenterology 2000; 47(31): p 57-70.

4. Silva E J, Seixas I V - Retocolite ulcerativa (RCU): perfil evolutivo clínico endoscópico. Estudo retrospectivo. Rev bras colo-proctol 2008; 28(1).

5. Macedo A L V et al - Hepatectomia a esquerda por colangiocarcinoma: relato de caso e revisão de literatura. Revista Einstein 2003; (1): p 23-5.

6. Sepúlveda S E et al - Enfermedad inflamatoria intestinal: Una mirada inmunológica. Rev. méd. Chile 2008; 136(3): p 367-375.
7. Loftus-Jr E V - Clinical epidemiology of inflammatory bowel disease: Incidence, prevalence, and environmental influences. Gastroenterology 2004; 126(6): p 1504-1517.

8. Souza M M et al. Perfil epidemiológico dos pacientes portadores de doença inflamatória intestinal do estado do Mato Grosso. Rev bras Coloproct 2008; 28(3): p324-328.

9. Teixeira W G J et al - Manifestações extra-intestinais após tratamento cirúrgico da retocolite ulcerativa. Rev bras Coloproct 2001; 21(1): p 9-18.

10. Mota E S et al - Manifestações extra-intestinais em doença de Crohn e retocolite ulcerativa: prevalência e correlação com o diagnóstico, extensão, atividade, tempo de evolução da doença. Rev bras colo-proctol 2007; 27(4).

11. Terg R et al- Prevalence of primary sclerosing cholangitis in patients with ulcerative colitis and the risk of developing malignancies: a large prospective study.Acta Gastroenterol Latinoam 2008; 38(1): p26-33.

12. Van Epercum K J, Van Berge Hergegouen - Hepatobiliary abnormalities in inflammatory bowel disease. Neth J Med 1989; 1: p40-49. 
Rev bras Coloproct

Janeiro/Março, 2010
Colangiocarcinoma Associado a Retocolite Ulcerativa:

Relato de Caso e Revisão de Literatura

Juvenal da Rocha Torres Neto e Cols.
Vol. 30

$\mathbf{N}^{\mathbf{0}} 1$
13. Hultcrantz $\mathrm{R}$ et al - A 3-year prospective study on serum tumor markers used for detecting cholangiocarcinoma in patients with primary sclerosing cholangitis. J Hepatol. 1999; 30(4): p669-73.

14. Ahrendt S A et al - p53 overexpression and K-ras gene mutations in primary sclerosing cholangitis-associated biliary tract cancer. J Hepatobiliary Pancreat Surg. 2000; 7(4): p426-31.
Endereço para correspondência:

JUVENAL DA ROCHA TORRES NETO

Rua Ananias Azevedo No. 100, apto. 902

Bairro Praia 13 de Julho, Aracaju- SE

E-mail: jtorres@infonet.com.br

Tel.(fax).: (79) 3214-4830 